\title{
Petition calls for federal funds for Cochrane
}

A

n online petition by Evidence for Democracy (E4D), asking the federal government to restore Cochrane Canada's funding, has about 2200 signatures a month after launching. The petition, which went live Jan. 21, urges Health Minister Dr. Jane Philpott to restore the \$2-million annual funding for Cochrane Canada.

That funding, which came from the Canadian Institutes of Health Research (CIHR), was cut in September 2015. CIHR had been Cochrane Canada's primary funder since 2005; the Ontario Ministry of Health and Long-Term Care contributed \$1 million over five years.

Katie Gibbs is cofounder and executive director of E4D, a nonpartisan organization promoting the transparent use of evidence in government decision-making. She says she is impressed by the rapid accumulation and number of signatures. "I think that shows just how concerned people are with the prospect of losing such a valuable information source, especially in the health community."

Cochrane Canada is one of 120 Cochrane programs around the world producing systematic reviews of research that promote evidence-based decisionmaking in health care. Cochrane Canada is the second largest contributor to the Cochrane Library, producing over 300 systematic reviews and updates in the past five years.

Gibbs says what makes Cochrane Canada's work unique and valuable is its independence. This is the kind of research that needs government funding "and it's these kinds of independent experts who make sure that the science gets translated in a way that

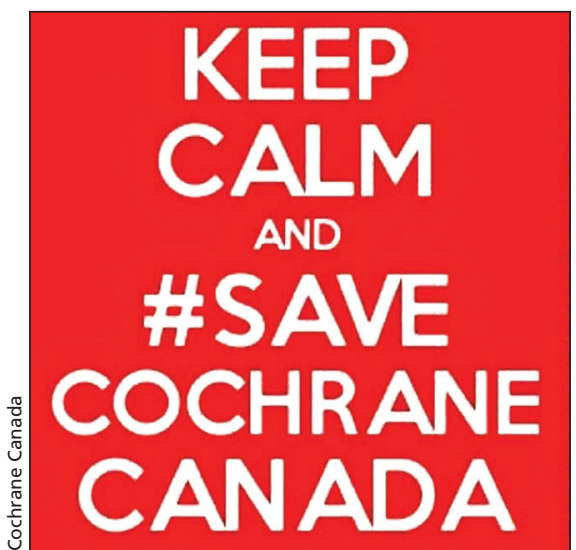

Support for restoring federal funding to Cochrane Canada is building through social media and, more recently, an online petition sponsored by Evidence for Democracy.

can be used to make effective personal or policy decisions."

After CIHR announced its cut, Cochrane Canada received support from an array of institutions and individuals through testimonials, CMAJ's lead editorial and through social media at \#saveCochraneCanada.

"The support has been overwhelming," says Dr. Jeremy Grimshaw, director of Cochrane Canada. "It is encouraging to see another organization championing our cause, especially an advocate with such a good reputation ... Their mandate is to bring the worlds of science and policy-making closer together, which is exactly what Cochrane does for health care in Canada."

Without Cochrane Canada, "we would be left making less-informed decisions," says Gibbs. "We'd end up Googling things and we all know the negative consequences of using random uninformed sources to make health decisions. In a time where we have a growing movement against vaccination and the like, access to evidence-based health information is essential."

In a previous CMAJ news article, a media representative for the CIHR stated that Cochrane Canada was "encouraged to apply for continued support through the same methods used by the CIHR to award funding to other world-leading scientific research.'

But when Cochrane Canada last applied to the CIHR's Open Operating Grant Program, they were told their "approach to research did not fit," according to information on the organization's website. Previously, Cochrane's CIHR funding came through direct grants; those were removed in late 2014 and no other CIHR funding program suits Cochrane's model.

"However, a number of factors are in our favour, including the new Liberal government's mandate," says Grimshaw. The government's move to focus on evidence-informed decisionmaking is highly aligned with Cochrane's work, he adds.

"If we want Canadians to make wellinformed decisions - whether they're physicians, patients, professionals or national policy-makers - we need to provide easy access to high-quality knowledge. That's what Cochrane does."

Reinstating Cochrane Canada's funding would be a great way for Philpott to show the Liberal government's support for science and evidence-based decision-making, says Gibbs. "Given the amount of support we've seen through the petition in combination with the new government's outlook, I'm cautiously hopeful that it will be in favour of Cochrane Canada." - Arianna Danganan, CMAJ

CMAJ 2016. DOI:10.1503/cmaj.109-5229 